\title{
Complex adaptive governance systems: a framework to understand institutions, organizations, and people in socio-ecological systems
}

\author{
Candace K. May' ${ }^{1}$ (D)
}

Received: 25 June 2021 / Accepted: 25 November 2021 / Published online: 17 January 2022

(c) Springer Nature Singapore Pte Ltd. 2022

\begin{abstract}
Governance is the reason for and solution to complex problems in socio-ecological systems (SESs). Governance refers to the institutions, organizations, and people involved in and affected by socio-ecological practices (SEPs), such as research, planning, design, construction, restoration, conservation, and management. The complexity of SESs requires the ability to understand and identify how the social world produces differential opportunities, constraints, and resources across multiple levels and scales of governance systems and as a consequence undesirable SEP outcomes for social equity, human well-being, and environmental integrity. This paper presents a complex adaptive governance systems framework (CAGS-F) designed to provide guidance, organization, and basic conceptualizations of social scientific concepts and terms for diagnostic, descriptive, and prescriptive inquiry into SEPs for the purpose of improving justice and sustainability. CAGS-F is unique for synthesizing the panarchy heuristic's focus on socio-ecological interdependence, cross-scalar, multi-causal, non-linear complexity, and change with compatible social scientific theories of multi-level institutions, organizations, and human practices. The framework works from a critical realist orientation to reveal how power and privilege embedded in institutions, organizations, and human practices produce inequitable and/or undesirable SEP outcomes. The structure of the framework employs analytic dualism to provide a way to identify where, at what level and scale, who is included and/or adversely affected, and at which point in discrete adaptive cycles across institutional, organizational, and human practices opportunities, barriers, and leverage points exist so as to optimize design, planning, programming, and implementation of SEPs or evaluate unintended and unforeseen, less than successful, inequitable, and/or undesirable outcomes.
\end{abstract}

Keywords Adaptive cycles $\cdot$ Critical realism $\cdot$ Panarchy $\cdot$ Intersectionality $\cdot$ Power $\cdot$ Stratification

\section{Capturing social complexity through governance}

Governance is both a reason for and solution to complex socio-ecological problems and injustices, requiring concerted consideration of the processes and outcomes of socioecological practice (SEP). Xiang (2019) conceptualizes SEP as the people and activities involved in planning, design, construction, restoration, conservation, and management in specific socio-ecological contexts to intentionally produce sustainable futures - human well-being, social equity, and environmental integrity. SEPs occur within complex socio-ecological systems (SESs), governed through multilevel, cross-scalar governance systems, consisting of institutions, organizations, and people. Therefore, successful SEPs require examination of the institutions, organizations, and people involved in or affected by SEPs. This paper contributes to SEP and SES research a complex adaptive governance systems framework (CAGS-F) founded on the panarchy heuristic of Gunderson and Holling (2002). The panarchy heuristic is widely popular for interdisciplinary SESs research (Cooke et al. 2021; Fischer et al. 2015; Reyers et al. 2018; Xu et al. 2015). However, a significant barrier to effective consideration of social systems in SESs research is

Candace K. May

ck.may@outlook.com

1 School of Psychology, Sociology and Rural Studies, South Dakota State University, Brookings, USA 
the sheer diversity of social theoretical and conceptual tools, which account for particular social elements at discrete levels and scales from multiple paradigmatic approaches, each with contradictory ontological and epistemological ${ }^{1}$ commitments.

CAGS-F synthesizes the panarchy heuristic and compatible social scientific theories within a critical realist orientation to reveal how power and privilege create discontinuous resistance and pressure for change across interdependent cross-scalar, multilevel complexes of institutions, organizations, and human practices. The purpose of CAGS-F is to guide integrated socio-ecological work toward progressive social change for just and sustainable futures by revealing barriers, opportunities, processes, and resources for considering and including diversity in experiences, knowledge, and circumstances in governance of SEPs. CAGS-F has potential to solve Forester's (2020: 118) fifth-generation theory-practice tension in SEP by providing a way to identify how power and privilege embedded in institutions, organizations, and people define "what matters, what's known, what's negotiable, and what has been ignored" to improve improvised problem solving in complex socio-ecological contexts. The popularity of the panarchy heuristic among a broad array of interdisciplinary scholars and practitioners (Chaffin et al. 2016; Cosens and Gunderson 2018; Fabinyi et al. 2014; Garmestani et al. 2020; Thoms et al. 2018; Winkel et al. 2020) increases the utility of CAGS-F for cross-disciplinary collaborations. At the same time, the sensitizing constructs for diversity, power, and privilege promote recognition and respect for difference across science/practitioner and nonscience/practitioner actors and contexts involved in and affected by decision-making processes to reveal invisible, previously ignored, or disregarded people, processes, and circumstances. The following sections of the manuscript explain (2) what CAGS-F is by explaining the constituent components of the framework; (3) what CAGS-F does through examples; (4) what is unique about CAGS-F; and (5) in conclusion, the benefits of CAGS-F for SEP.

\footnotetext{
1 Ontology refers to beliefs about the nature of reality and what reality is; epistemology refers to the relationship between the knower and what is and can be known; each varies across scientific paradigms (Guba and Lincoln 2005). In short, positivism sees reality as observable and measurable from the standpoint of detached, value neutral scientists; interpretivism sees reality as multiple and constructed, knowable only from the perspective of people experiencing it; and critical science sees reality as observable and measurable, but multiple and varying requiring the perspectives of affected people to understand - and change.
}

\section{What is CAGS-F?}

CAGS-F is a framework, designed to provide guidance, organization, and basic conceptualizations of concepts and terms for diagnostic, descriptive, and prescriptive inquiry ${ }^{2}$ into SEPs for the purpose of improving justice ${ }^{3}$ and sustainability. The focus on governance in CAGS-F narrows attention to the specific institutions, organizations, and people involved in and affected by SEPs in particular contexts from among the universe of all potential units of analysis. Governance is the formal and informal political administrative, economic, and social institutions and organizations through which power and authority are held and diverse stakeholders and user groups negotiate access, use, and allocation of natural or social resources (May 2015). Hence, governance is the particular institutions, organizations, and people that determine resource access, use, and allocation, and as a consequence authority, equity and justice, and environmental integrity through specific SEPs.

The focus on adaptive governance in CAGS-F derives from widely recognized need for system change to achieve just and sustainable outcomes (Abrams et al. 2020; Brunner 2010; Chaffin et al. 2016; Folke et al. 2005; Karpouzoglou et al. 2016; Walker et al. 2004). Organizations, institutions, and the distribution of resources and opportunities among social groups are the product and structural reflection of past political actions, knowledge systems, and power relations, which result in current procedural, (mis)recognition and representational, and distributional inequities but are amendable to change for improved socio-ecological welfare, equity, and integrity. As Shi (2020) explained, achieving SEPs' progressive goals of justice and sustainable development requires collaborating with and considering the needs and desires of diverse groups by race, ethnicity, indigeneity, nationality, immigrant status, age, ableness, sexuality and gender identity, as well as diverse disciplines, such as sociology, race and gender studies, agriculture, and public health. Collaborating with and considering the needs of diverse groups requires a coherent framework to guide examination of how institutions, organizations, and people produce unintended or undesirable outcomes, differential barriers and

\footnotetext{
${ }^{2}$ McGinnis and Ostrom's (2014: 1) definition of framework.

3 Justice concerns (at a minimum) procedural/participatory equity, distributional equity in benefits and costs, and recognition/representational equity. Recognition confers dignity, while a lack of recognition is a refusal of others' humanity with significant consequences for identity formation and life chances (Fanon 1986, Honneth 1995). Young (1990) explained how non-, mis-, or malrecognition of people, communities, and conditions are the core reason for injustice, oppression, and domination, and Fraser (1995) accentuated the importance of recognition as a prerequisite for procedural/participatory parity and, as a consequence, distributional equity for the previously discriminated against, derided, or ignored.
} 


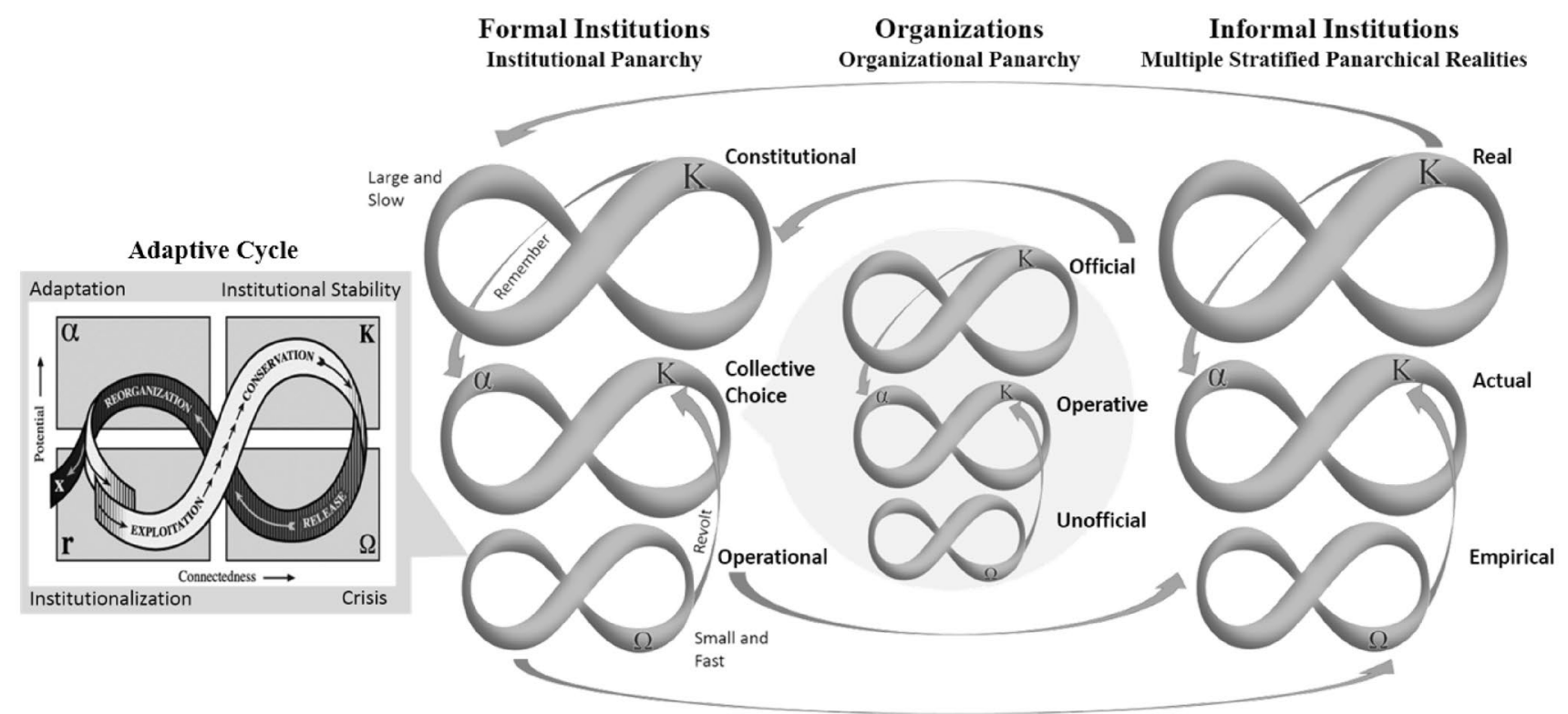

Fig. 1 Complex adaptive governance systems framework (adapted from Gunderson and Holling 2002: 14 and 75 and May 2021a: 4)

opportunities, and resources and leverage points for achieving progressive goals, including inclusionary practices. CAGS-F is that coherent framework. GAGS-F synthesizes Gunderson and Holling's (2002) panarchy heuristic with compatible theories of institutions, organizations, and intersectionality and stratification within a critical realist orientation to visualize how dynamic and discontinuous processes, structures, and practices produce pressures and resistance to change across levels and scales of governance systems.

\subsection{What is the panarchy heuristic?}

Figure 1 illustrates Gunderson and Holing's (2002) adaptive cycle and panarchy heuristic modified to represent the formal institutional, organizational, and informal institutional elements of CAGS-F. ${ }^{4}$ Panarchy refers to hierarchically ordered, connected, and interlocking complexes of adaptive cycles across multiple levels and scales. The panarchy heuristic was developed to explain resilience - the ability of a system to resist, adapt, or transform to a new resilience regime in response to internal (i.e., political turmoil) or external (i.e., natural disasters) shocks and disturbances. Resilience is the outcome of pressures and constraints generated by interdependent, but discontinuous adaptive cycles operating at multiple levels and scales. Adaptive cycles involve four phases, which in Fig. 1 (far left) are labeled with

\footnotetext{
${ }^{4}$ Conceptualizations of terms across each CAGS-F component are provided in a Table 2 in the Appendix.
}

additional terminology for a more natural association with social systems (May 2021a). ${ }^{5}$ Crisis $(\Omega)$ refers to a shock or disruption, such as natural disasters, economic crisis, technological innovation, or development projects. Adaptation $(\alpha)$ is the reactionary or anticipatory response to crises, such as disaster preparedness planning, social mobilization, or environmental conflict resolution. Institutionalization (r) is a process where actions and expectations become patterned and recurring with prospects for continued and future resource access, use, or allocation in infrastructural development processes, policies, or final plans. Institutionalized stability $(\mathrm{K})$ exists when understandings, expectations, and actions are routinized over time.

Gunderson and Holling's (2002) panarchy model (Fig. 1) illustrates three levels of adaptive cycles, which change at varying speeds. Higher levels exhibit slower speeds and exert greater constraint and authority at broader spatial, temporal, jurisdictional, or conceptual/analytical scales. Lower levels change faster and exert less constraint and authority across smaller scales. Top-down constraints and bottom-up pressures for change are depicted in the left-hand panarchical system of Fig. 1 by remember and revolt connections. Larger and slower components of the hierarchy provide memory and resistance to change, which encourages smaller and faster adaptive cycles to return to a stability state after a perturbation. However, adaptive responses at any level

\footnotetext{
$\overline{5}$ The order of phases is not set; transitions have been observed between all phases, except from release $(\Omega)$ directly to conservation (K) (Walker and Salt 2006: 78).
} 
or scale have the potential to cause or resist change at any other level or scale (Gunderson and Holling 2002). CAGS-F conceptualizes each component of governance systems as a panarchical system, interdependent and connected to the other components. Socio-ecological disruptions, including SEPs are preceded, concurrent with, and followed by a series of adaptive responses (pressures, constraints, and processes) within and across the hierarchical, multi-level complexes of formal institutions, organizations, and informal institutional domains (shown in Fig. 1) and the practices of people.

\subsection{What is institutional panarchy?}

The first component of CAGS-F is formal institutions, represented by the Institutional Panarchy Framework (IPF) (May 2021a) in Fig. 1. Institutions are formal or informal rules or norms that proscribe, prescribe, or require certain actions and associated consequences for noncompliance (Crawford and Ostrom 1995; Schlager and Ostrom 1992). ${ }^{6}$ Formal institutions are codified, documented, explicit rules generally enforced through bureaucratic and hierarchical authority structures, such as laws, legislation, and treaties (North 1991). The IPF conceptualizes the three levels of formal institutions identified by Ostrom and colleagues as hierarchically related to the next, with decreasing scope in scale and influence, but increasing rates of change. Constitutional rules designate authority relations at the highest level, with influence across the broadest scale, and set the parameters for lower level institutions (McGinnis and Ostrom 2014; McGinnis 2011; Ostrom 2011). Policy/collective choice level rules at the meso-level delimit processes and procedures for decision-making and the roles of actors involved (McGinnis and Ostrom 2014; McGinnis 2011; Ostrom 2011). Operational rules at the lowest level guide every day, practical activities, decision-making, and problem-solving processes for individuals or small collectivities (Crawford and Ostrom 1995; Schlager and Ostrom 1992). According to Kiser and Ostrom (1982) design, implementation, and enforcement of rules at constitutional and collective choice levels control the operational world of action (Kiser and Ostrom 1982). In contrast to Ostrom and colleagues, IPF conceptualizes the institutional levels as complex, interdependent, and dynamic, characterized by multi-directional causality; adaptive responses at any level or scale have the potential to cause or resist change at any other level or scale. For example, May (2021a) showed how operational level innovations in public access and use of nonmeandered waters (NMWs) overlying private agricultural lands in South Dakota resulted in collective level adaptations in court decisions and House bills, ${ }^{7}$ followed by constitutional level changes in statutory laws.

\footnotetext{
${ }^{6}$ Informal institutions are discussed separately below.

7 Bills introduced for consideration as law.
}

\subsection{What is organizational panarchy?}

The second component of CAGS-F is organizations. Institutions provide rules for actions, but are not actors nor the arenas where actions occur. In contrast, organizations are actors, as well as arenas for action. ${ }^{8}$ Perrow (1986) contended that organizations change in response to social and institutional environments and as a result of differential rates of change among three levels of goals internal to organizations and the discretion of people filling roles. In Fig. 1 (center), official goals are at the highest scale, with greatest scope of authority, but most abstraction and slowest rate of change. Perrow (1961) defined official goals as the general purposes of the organization as stated in charters, mission statements, annual reports, and public statements by key executives and other authoritative pronouncements. Operative goals define the actual operating policies of the organization in delineating means and resources and prioritizing objectives in achieving official goals. Unofficial goals evolve at the fastest rate of change with the preferences, interpretations, capabilities, and power struggles of personnel in everyday problem solving and role fulfillment. Perrow's (1986) concepts of goal displacement and drift capture discontinuity across official goals, which change slowly and operative and unofficial goals which change faster. For example, May (2021a) showed how adaptations in the unofficial goals of the SD Game, Fish, and Parks (GFP) agency to facilitate public access and use of NMWs resulted in changes in agency operative goals, followed by changes in official goals for managing public use and access to NMWs.

\subsection{What are informal institutions and multiple stratified panarchical realities?}

Informal institutions are a third component of CAGS-F. In contrast to formal institutions, which are manifest, easily observable in documented legislation, law, policy, organizational mission statements, workload documents, and contracts, informal institutions are latent, undocumented, implicit, often tacit norms, understandings, and expectations enforced through social relationships (North 1991).

\footnotetext{
8 Organizations as actors and arenas for collective action is signified by placement at the collective choice level in Fig. 1. Organizations are constrained and constituted by institutional environments, such as laws and legislation, but also define and redefine the social and natural environment in the process (Zucker 1982). Organizations enter into collective choice arrangements in governance systems, often with a higher degree of authority than local individuals or groups and lower degree of authority than legislation and laws. They operate at operational institutional levels and work to alter constitutional institutional arrangements. Organizations are also arenas for collective decision-making processes with more or less structured roles and hierarchical levels of authority, which do not fully control for human ingenuity, cooperation, and conflict in carrying out organizational goals and objectives (Perrow 1986; Selznick 1949).
} 
Bhaskar's (2008) critical realist approach provides a way to understand informal institutions that is highly compatible with Gunderson and Holling's (2002) panarchy heuristic. The premise of Bhaskar's (2008) critical realism is the a priori existence of an independent material or nonmaterial reality, which is necessary for acting in and producing knowledge of the world. However, as Carolan (2005) explained, what we know and think is not assumed to be the same as what is, the deep, enduring, yet mutable, biophysical and social tendencies that give events weight and meaningful structure. Building on Bhaskar's (2008) critical realism, informal institutions have essential properties that operate continuously, regardless of immediate effect and irrespective of any one person's acknowledgement. We know the underlying causal mechanisms of informal institutions are real from the effects on human behaviors, circumstances, and life chances. ${ }^{9}$

Based on the logic of latent casual social conditions, Bhaskar (2008) concluded that the social world is stratified into at least three levels, which are labeled on the right-hand panarchical system in Fig. 1. The levels are: the empirical at the lowest level, where events are easily observed and measured; the actual, where events require a more concerted effort to discern and explain; and the real or the deep at the highest level, where nearly unobservable tendencies provide weight and meaningful structure to the social world. ${ }^{10}$ The panarchy heuristic adds a way to understand different rates of change across each level of reality and a way to examine variable effects across scales. Change is fastest at the empirical level, where effects have a narrower scope, while change is slower at the real level, where effects are broader in scale. For example, while constitutional institutions and formal organizational goals bar race as a basis for discrimination in present day USA, the persistence of racism is real across different levels of institutions, organizations,

\footnotetext{
${ }^{9}$ Life chances is a probabilistic concept coined by the German sociologist, Max Weber (1978: 929) to explain the opportunities that produce life circumstances. It explains an individual's life circumstances as an outcome of opportunities -access to material resources, such as food, clothing, shelter, and safety, and immaterial resources, such as education, nutrition, and health care. Life chances shapes individuals' abilities to improve their circumstances via access to additional resources, career opportunities, and general ability to satisfy needs and achieve goals.

10 The structure and processes of Bhaskar's stratified reality parallel the panarchy framework, beginning with the key characteristics of rootedness and emergence. Bhaskar (2008) theorized that higher level, real phenomena are rooted in, and emergent from, more basic empirical phenomena, which implies multidimensional feedback effects. Like Gunderson and Holling's (2002) panarchy heuristic, the emergence of higher-level phenomena from lower level strata does not preclude higher levels from exerting influence on lower levels. Reality is stratified, emergent, and open to dynamic tendencies from both above and below (Carolan 2005)
}

and relationships, manifesting through actual disparities in public health, income, occupational, and opportunities to be heard, seen, and considered in decision-making processes, and empirical everyday interactions, relationships, challenges and successes, and collective mobilization for change toward racial equity. The difficulty in this analysis is that realities are not just stratified, but multiple.

\subsubsection{How do we recognize multiple stratified realities?}

The stratified panarchical realities perspective has utility for examining the structures and mechanisms of informal institutions, and their influence on how formal institutions, organizations, and people produce differential experiences and inequitable life chances. However, the visibility of how latent power and privilege operate through institutions and organizations and how realities are stratified and multiple requires recognition, respect, and representation of the perspectives, experiences, and knowledge of people from diverse backgrounds. Intersectional scholarship in climate, development, water, and other justice research (Djoudi et al. 2016; Gonda 2017; Kaijser and Kronsell 2014; Nightingale 2017; Schlamovitz and Becker) employs a relational, multiple realities approach. Relational approaches focus on how latent, structural, and institutionalized power is discontinuously and unevenly experienced and reproduced across space and time (Sultana 2020). Multiple realities approaches emphasize differential power to interpret, implement, monitor, and enforce institutions through the machinery of organizations and everyday social relations that produce differential barriers, opportunities, resources, and leverage points for change in SESs.

Critical realist, intersectional scholarship (Flatschart 2017; Martinez et al. 2014; Walby 2007; Walby et al. 2012) provides a way to conceptualize and operationalize multiple stratified realities. According to Martinez et al. (2014: 14), abstract categories, such as racism, sexism, and classism, as well as intersectional mechanisms (such as the notion of misogynoir, the misogyny directed specifically at black women and girls) are real, emergent structures. These real structures position individuals and groups within social hierarchies with actual consequences for enabling or constraining life chances which manifest as empirical tendencies in everyday interactions, conflicts, challenges, and successes. Critical realist, intersectional approaches reveal how much of the social world is latent, embedded in and enacted out of tacit knowledge, habituated actions, and power relations, and differently experienced across groups involved in and affected by SEPs.

The focus on institutional and organizational panarchy from the perspective of critical intersectionality reveals how legislation, policies, and bureaucratic imperatives and processes produce unanticipated and/or undesirable differential 
outcomes. As Ray (2019) explained, real relations of power, privilege, and domination are produced and reproduced through organizations and institutions, inclusive of but irreducible to individual actions. For example, part of the perpetuation of environmental racism is a lack of diversity in people fulfilling positions of authority in environmental nongovernmental organizations and foundations (Taylor 2015). People in positions of authority matter. Organizational goals created in the past, such as those that supported discriminatory housing practices based on redlining are responsible for persistent inequities in life chances related to residential segregation (Rothstein 2017), and are reproduced or challenged by people carrying out unofficial organizational goals. People, intentionally or unintentionally, carry preferences, knowledge, and experiences into roles, which shape organizational performance and broader responses to pressures and resistance to change. Nevertheless, structures of power and privilege are embodied by but exist separate from people as latent institutional features representative of diverse, multiple realities. Additional tools are needed to observe and measure how people with differential capacities produce, reproduce, or challenge system characteristics across manifest, easily observable social domains, as well as those that are latent, disregarded, and ignored.

\subsection{How do human practices contribute to system dynamics?}

People are the final component of CAGS-F. People occupy diverse standpoints informed by diverse experiences of reality, have different and differently valued skills and experiences, and, as a result, unequal power and opportunities to benefit from, be involved in, or effect governance processes. Bourdieu's (1990) practice theory offers an approach that recognizes the embeddedness of humans in socio-natural environments, as well as how stratification and intersectionality shape capabilities, capacities, and life chances differently across space. A summary of Bourdieu's (1984: 101) theory is provided by the equation, [(habitus) capital) $]+$ field $=$ practice. According to Bourdieu (1990), the practices of individuals or social classes ${ }^{11}$ are both structured and enabled by their habitus and the capital

\footnotetext{
11 The term "social classes" or "social groups" (Bourdieu 1990) is used to avoid the normative complications associated with conceptualizations of communities as locally, bounded, homogenous social entities constituted of people with shared histories, experiences, and interests (Agrawal 1999, Collins 2010, Leach et al. 1997). However, homogenizing groups based on common classification schemes for races or ethnicities also needs to be avoided (Brubaker 2002); groups
}

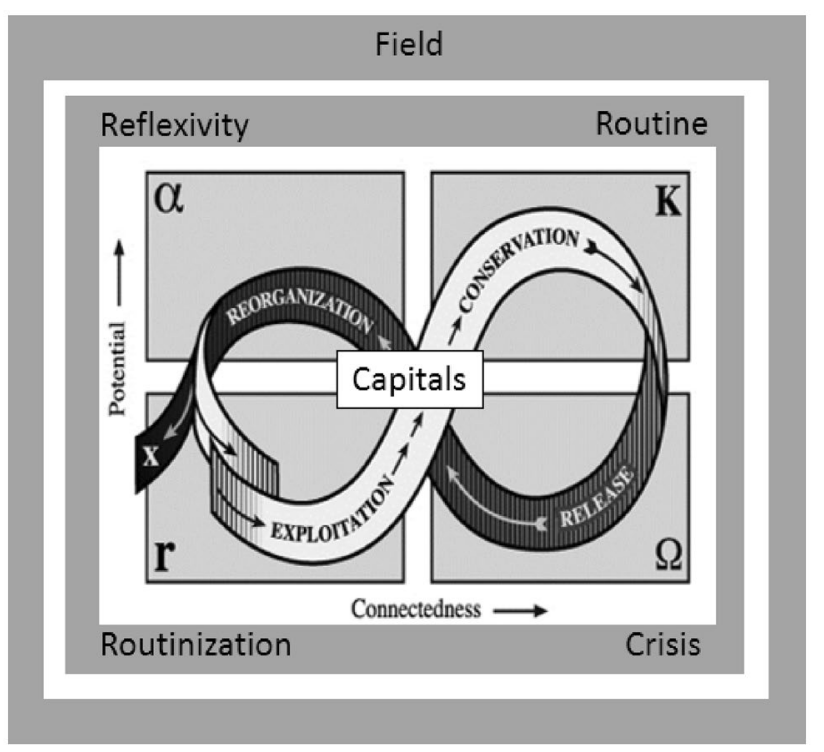

Fig. 2 Habitus and change

resources they have control and/or access to across fields. Capital resources include equipment, property, credit, or money (economic capital), skills, knowledge, ways of seeing, understanding, and doing (cultural capital), and means of accessing additional resources through social networks (social capital). People use and deploy capital assets according to dispositions, perceptions, and appreciations (habitus) in competitive contexts (field) defined by stratified positions of prestige and explicit and implicit rules, boundaries, and objectives for the use and valuation of capitals. For example, small-scale fisherpeople's habitus and capital resources emerge from and are highly useful for tracking elusive fish through vast, opaque habitats and designing and enforcing informal institutional understandings for use, allocation, and access to fishery resources for maintenance of fisher livelihoods, but are often undervalued and less effective in formal fishery policy processes relative to competing user groups (May 2015, 2021b).

An important consideration for the applicability of Bourdieu's theory to understanding adaptations in SESs concerns the capacity for habitus to change. Habitus is a determining factor in how people deploy resources, identify truth, and set goals. ${ }^{12}$ Bourdieu's theory has been described as overly structural and deterministic; habitus was understood,

\section{Footnote 11 (continued)}

identified by sex, race, ethnicity or any other single measure of diversity are frequently extremely diverse. Comparatives should be based on similarities in habitus and life chances.

12 Habitus is inseparable from the resources people control and/or have access to, as well as the particular socio-ecological fields that reinforce the differential importance of variable resources. 
as Sewell (1992: 15) noted, to be "agent-proof." However, while habitus is durable, it is not immutable (Bourdieu and Wacquant 1992). Reflexivity has potential for altering objective structures (Archer 2003), such as habitus. Figure 2 was designed to illustrate an adaptive cycle for habitus, where an event, shock, or disruption spurs reflexivity, routinization of an adaptive response, and a potential consequent change in habit or routine. Reflexivity instigated by new, challenging, or altered experiences creates opportunities for change in habitus in the same way crises spur adaptive cycles in panarchical systems (Gunderson and Holling 2002) or threatened ontological security decreases trust, and as a result decreases continuity of self-identity and routine in social and material environments (Giddens 1990). Bourdieu's (1990) theory emphasizes the relationality of practice and reflexivity in how changes in consciousness, relations, and resource access and use can reinforce, challenge, or transform resilient manifest rules and goals and latent assumptions, preferences, and understandings embedded in institutional and organizational logics.

\subsubsection{How is human practice panarchical?}

Practice and reflexivity operate across panarchical systems. The tacit assumptions, preferences, and understandings that partially constitute habitus (peoples' dispositions, perceptions, and appreciations) signify the existence and workings of informal institutions. These structures exist a priori to contemporary contexts and are reflected to varying degrees in formal institutional and organizational logics, but can evolve through practice and reflexivity among individuals and social groups. A panarchical practice model for habitus with implications for broader scale change across institutions and organizations positions tacit knowledge at the highest level. Saint-Onge (1996) defined tacit knowledge as unarticulated knowledge, constituted by the intuition, perspectives, beliefs, and values that people form as a result of experiences and socialization. Tacit knowledge is the filter for interpretations, understandings, and behavior and goals, as such, it is the basis for most individual decisions and practical activity. Giddens (1984) positioned everyday, practical consciousness as the middle ground between tacit (unarticulated) and explicit (articulated) knowledge. Whereas tacit knowledge is unconscious and inarticulable, practical consciousness is semi-articulable. Discursive consciousness operates at the lowest level with narrowest scope, reflecting what people can fully articulate regarding the world and their actions and circumstances (Giddens 1984). Everyday practical and collaborative problem solving, disruptions from broad-scale economic, natural, technological, or social shocks, or new experiences spur reflexivity and the possibilities for learning and change as the invisible, tacit aspects of norms, preferences, and expectations become visible and discursive. ${ }^{13}$

For example, Bourdieu's (1990) theory adds to collaborative learning, or co-productive governance processes (for example, Abidi-Habib and Lawrence 2007; de Kraker 2017; Fernández-Giménez et al. 2019; Kondo et al. 2021; Tschakert et al. 2014; Turnhout et al. 2020; Wyborn 2015). The habitus and capital assets of individuals shape and are affected by the iterative processes of experimentation and learning in defining problems, identifying solutions, implementing strategies, and assessing outcomes in group settings. Theoretically, change and transference of material/ economic capital (money, credit, tools, and technology), social capital (resources accessible through social relations), and cultural capital (skills, knowledge, and ways of knowing) occur as relationships develop and grow or splinter and disintegrate. The degree of trust, reciprocity, and mutual understanding and respect involved in relationship building causes either an increase, decrease, or qualitative change in asset access, investment, or development. For example, in a comparative study of coastal community resilience in the USA, recognition and respect proved to be the difference between diverse, stratified groups cooperatively pooling differential capital assets to respond and recover from socioecological hazards in Louisiana, while conflict, distrust, and exclusion diminished adaptive capacity in North Carolina (May 2021b). However, individual and group practices alone were not sufficient to explain community resilience in North Carolina or Louisiana. Recognition and respect, or the lack thereof, embedded in institutional, formal and informal, and organizational systems enabled outcomes for both cases (May 2021b). CAGS-F emphasizes the relational processes of panarchical practice (resources and the stratified positioning of actors based on power and privilege) in and across fields (governed by formal and informal rules and consisting of organizations and other individuals) as central for how reflexivity reinforces, challenges, or transforms tacit and explicit assumptions, preferences, and understandings as discursive consciousness expands, thereby creating opportunities and revealing needs for institutional and organizational change.

\section{What does CAGS-F do?}

CAGS-F draws attention to how power and privilege produce resilience (resistance, continuity in change, or transformation) through complex interdependence and multi-directional causality across institutions, organizations, and people

\footnotetext{
13 Importantly, this process includes scholars, scientists, and practitioners, who also engage in processes of critical reflexivity and learning across fields with diverse logics, within and outside the domains of science (Xiang 2019: 8, footnote 7).
} 
involved in and affected by SEPs. Institutional systems of power and privilege are apparent through whose knowledge, skills, experiences, and environmental objectives are represented and recognized in the rules (institutions) and goals (organizations) that structure decision-making processes, which denote differential valuations of capital resources and, as a consequence, produce differential opportunity structures for participation and inequitably distributed risks and benefits. Together, the theories synthesized in CAGS-F facilitate an examination of emergent causal mechanisms and pressures and constraints as diverse groups navigate, contest, reinforce, and renegotiate structures and relationships of power and privilege across institutions and organizations. An example is provided by a study of institutional adaptations in governing public recreational use and access to nonmeandered waters (NMWs) overlying private agricultural lands in the South Dakota Prairie Pothole Region (SD PPR) (May 2021a). ${ }^{14}$ In addition to demonstrating complex interdependence and multi-directional causality across institutional and organizational panarchical systems, the NMWs study stresses information needs for involved and affected groups. Information for each domain of CAGS-F for the NMWs case is summarized in Table 1 and explained in the following sections.

\subsection{CAGS-F reveals dynamic processes across institutions \& organizations}

Development of NMWs governance in the SD PPR was shaped by property rights for land and water and political economic dependence on agricultural and nature-based tourism at the initial conservation (K) stage of the constitutional institutional level. Most NMWs in the SD PPR are intermittent wetlands, overlying private agricultural land. All water in SD is publicly owned, but NMWs have historically lacked the size, depth, and permanency to require definitive rules for public access and use. This ambiguity created conflict over access and use of NMWs following a crisis $(\Omega)$ in the 1990s when a heavy wet cycle caused the dramatic expansion of NMWs. People used newly accessible public access points and trespassed over private property via significantly shortened distances to hunt, fish, boat, and generally enjoy the expanded opportunities for outdoor recreation on NMWs. These activities denoted reorganization $(\alpha)$ in operational institutions by the public for use and access to NMWs. In the organizational domain, the state sanctioned Game, Fish, and Parks (GFP) agency reorganized operations to manage public access to NMWs $(\alpha)$ by contributing to fish populations, expanding public access points (r), and

14 See May (2021a) for an explanation of data, data collection, and analysis methods. developing infrastructure and maintaining fisheries $(\mathrm{K})$ for public use of NMWs. These responses demonstrated adaptations in unofficial organizational goals; GFP personnel did not, at the time, have official authority to manage NMWs for public use.

Adaptations in operational institutional rules by the public and the unofficial goals of GFP caused a crisis $(\Omega)$ at the collective choice level. Landowners mobilized through the court system to reinforce their rights to control access and use of their property. Court decisions spurred collective choice level institutional adaptations: a Legislative Summer Study was convened $(\alpha)$, resulting in a House bill (r), and resumed access to the waters with requirements for negotiated access and use rights with landowners $(\mathrm{K})$. The operative organizational goals of GFP were altered to accommodate the new responsibility for negotiating public access and use rights to NMWs with private landowners. These collective choice level changes resulted in a new stability state (K) at the constitutional institutional level. NMWs gained statutory legal status as a resource in need of management for public use and access, and the statutory authority of GFP was expanded to include public recreational management of NMWs. The expansion in authority was then incorporated into GFP's official organizational goals. The organizational and formal institutional adaptations in governance of SD NMWs demonstrate how change at lower institutional and organizational levels causes change at higher levels and broader scales (May 2021a). The interplay of human ingenuity in operational institutions and unofficial organizational goals reflected important processes of goal displacement, which caused pressure for change across organizational goals and higher institutional levels.

\subsection{CAGS-F reveals human practice from multiple stratified realities}

Prominent groups in the SD PPR affected by the NMWs include farmers, recreational interest groups, rural communities, Indigenous people to the region, ${ }^{15}$ and Hutterite

\footnotetext{
15 South Dakota is located on the ancestral, traditional, and contemporary lands of the Oceti Sakowin - Seven Council Fires - which includes the Santee-Dakota, Yankton-Nakota and Teton-Lakota. The SD PPR, which constitutes the entire eastern region of SD, is home to 21 percent of the Native population and four of nine federally-recognized Native Nations.
} 


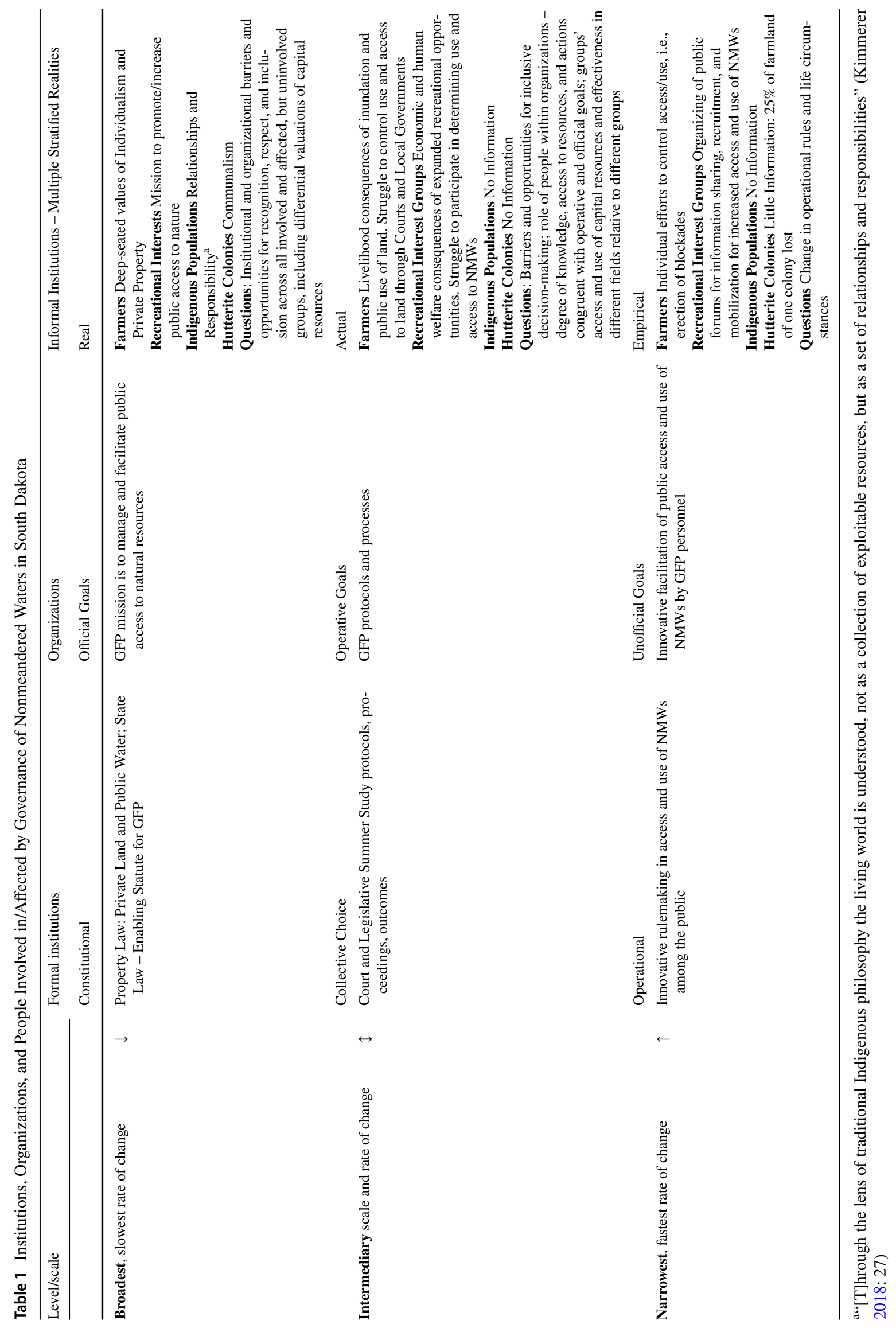


Colonies. ${ }^{16}$ The data collected for the NMWs case demonstrated the active and effective involvement and representation of farmers and recreational interests groups in processes to determine access and use of NMWs through public forums, lawsuits, and the Legislative Summer Study (May 2021a). Farmers and recreational interests groups benefited from capital assets useful for organizing (economic resources, such as money), leveraging relations (extensive social connections, including among state legislators), and traversing public political forums (cultural resources related to education, experience, and skills). In addition, broader political economic imperatives exerted pressure toward a speedy resolution. Discussions during the Legislative Summer Study revolved around the economic importance of agriculture and nature-based tourism (May 2021a). There was no evidence, however, of how indigenous people or Hutterites were involved in or affected by the NMWs issue, beyond a report of one Hutterite Colony losing 25 percent of its farmland to expansion of NMWs (May 2021a). No organized data sources exist on how rural communities, livelihoods, or farms by various sizes, tenancy, commodity production, or operator demographics, such as sex or race, were impacted by the hydrological changes that caused the NMWs issues in the SD PPR (May 2021a). The general invisibility of diverse groups in political deliberations, media reports, and data is indicative of how generalized, tacit institutional norms, understandings, and expectations operate through formal institutional and organizational domains to define who and what matters through simple inclusion or omission from consideration.

CAGS-F helps to examine constraints and opportunities, processes, and outcomes of governance systems for groups who are involved, as well as those who are affected but absent from governance processes. Understanding the absence of indigenous people and Hutterites from participation and consideration in NMWs deliberation processes requires an examination of the multiple levels of institutional and organizational logics, as well as human practices. Questions concerning the formal institutional levels include: How have operational rules changed for various groups, what are the barriers and opportunities at the collective choice level for airing concerns, how do these barriers and opportunities align or contradict with the constitutional level? Questions concerning the organizational levels include: How are people fulfilling roles within organizations aware of and responding to the changing circumstances of

\footnotetext{
${ }^{16}$ Hutterites are an ethnoreligious communal group of Anabaptists who, like the Amish and Mennonites, trace their roots to the Radical Reformation of the early sixteenth century (Vonk 2011). On average, each colony consists of 80 people in 14 families who hold all material goods in common and rely on farming and light manufacturing (Evans and Peller 2015). The SD PPR is home to $46 \%$ of the US Hutterite population (May 2021b)
}

different groups, with what resources, and under what directives, and how do these activities align with or contradict operative and official goals? Questions concerning informal institutions and the practices of people operating from multiple stratified realities include: What capital resources do groups have; how are they employed, why, and with what effectiveness for problem solving in different fields relative to different groups; and, how do different institutional and organizational logics create barriers and opportunities for recognition, respect, and inclusion of different groups, including how different capital resources are valued? These questions, although not exhaustive, allow for comparative analyses of groups across institutional and organizational systems to reveal connections representing contradictions, similarities and differences, and causal relationships in differential opportunities, constraints, and resources implicated in recognition, representation, or participation.

\section{What is unique about CAGS-F?}

CAGS-F is a systems approach for revealing dynamic barriers, opportunities, and resources across multiple scales and levels of institutions, organizations, and people, which can be used as leverage points for achieving environmental justice and sustainable development through SEPs. While many frameworks have similar objectives and features, CAGS-F is unique for integrating (1) socio-ecological interdependence, complexity, and change (2) within a critical realist orientation (3) with a focus on stratification and intersectionality (4) and analytic dualism. An example model of CAGS-F is depicted in Fig. 3. CAGS-F draws on the strengths of the widely used panarchy heuristic to conceptualize and track interdependence and discontinuous pressures and constraints to change across and within multiple levels and scales of institutions, organizations, and people. The material, natural world surrounds the social world in CAGS-F to denote socio-ecological integration and embeddedness, but more importantly to emphasize the material basis of human beliefs, perceptions, preferences, relations, and capital resources, even if knowledge is never fully complete or accurate. The social world includes deep-seated mechanisms of foundational ideologies, power, and privilege at the scale of real and habitus, capitals, and fields at the scale of the empirical to draw attention to diverse, multiple realities. Capital resources are modeled as an integral connector between human adaptations and habitus to emphasize human responses and capacities as an outcome of preferences and dispositions, the resources people have access to, and the rules and relations of particular socio-natural contexts. 


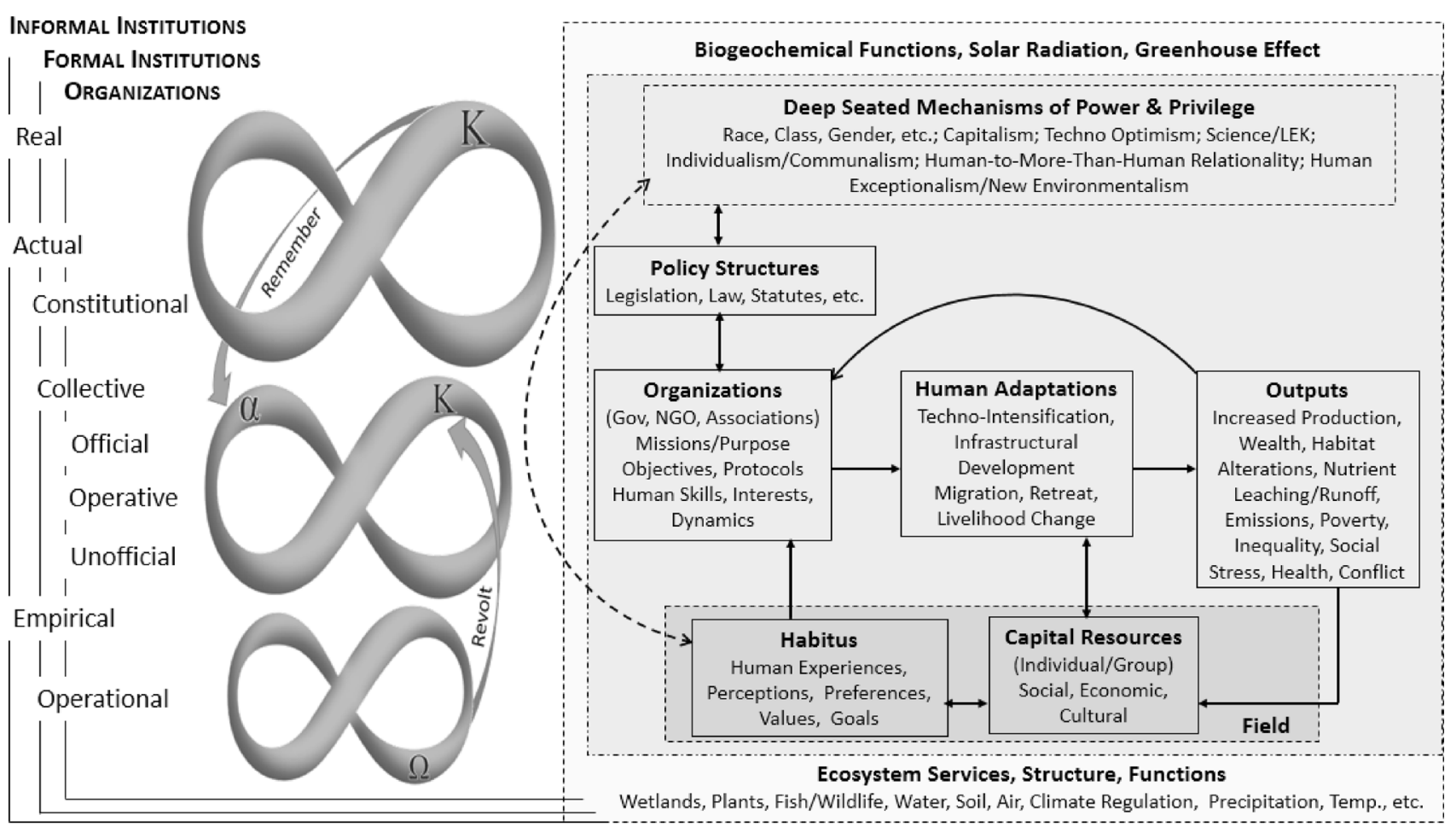

Fig. 3 Example complex adaptive governance system

The critical realist orientation helps to reveal objective structures in society, including power, privilege, and stratified opportunities and barriers, which are not entirely recognizable to scientists or practitioners working from traditional scientific uninvolved, detached, value neutral standpoints. As Smith (1990), and many feminist, indigenous, and critical race scholars (see for example, Blaser 2014; Goldman, Turner and Daly 2018; Nightingale 2016; Prescod-Weinstein 2020; Tschakert 2012) have demonstrated, the ontological and epistemological standpoints of scientists and practitioners shape the rules and methods of science, the findings that inform policy, programs, and projects and, as a consequence, distributional life chances in society. For example, Hoover and Lim's (2021) discussion of the double crises of antiblack racism and COVID-19 showed how racialized, gendered, and other experiences are embedded in physical landscapes, built environments, and social structures, as well as the corresponding processes of designing, managing, or studying them, which reproduce power, privilege, and social injustices. The critical realist orientation encourages openness to assessing assumptions, including those foundational to science, and understanding how reality varies by what is known, acknowledged, and experienced among scientists, practitioners, and the people involved in and affected by science, planning, and design. Critical stratification and intersectionality perspectives encourage us to ask who is missing, who is excluded, who needs to be included, and what changes are needed for more inclusive SEPs capable of promoting human welfare, social equity, and environmental integrity. CAGS-F emphasizes how reality is not just stratified, it is differential and dynamic across human populations by intersectionalities of wealth, power, and prestige within and across formal and informal institutional and organizational contexts.

While manifest institutional and organizational logics are relatively easier to observe with the assistance of traditional theories and frameworks, observation of latent institutional, organizational, and differential relational structures, processes, and practices requires the perspectives and experiences of groups from diverse backgrounds and experiences. Bourdieu's (1990) practice theory focuses on emergent relations and practices among and across diverse and stratified social groups with differential capacities navigating constraints, producing contradictions, and driving processes of change, resistance, and transformation within, external to, and across institutional and organizational domains of CAGSs. Following Bourdieu (1985), the invisible becomes visible when analysis proceeds from the individual level to 
social classes representing groups with similar life chances and eco-habitus characteristics. This bottom-up approach combined with institutional and organizational panarchy analyses facilitates a comparative examination of adaptive cycles across everyday practices, roles, responsibilities, and differential access to and use of resources (empirical and operational institutional fields and unofficial organizational goals); relations within collective action contexts to other groups and policy structures and outcomes (the actual and collective choice institutional fields and operative organizational goals); and deeper mechanisms of power and privilege (real and constitutional institutional fields and official organizational goals).

Finally, the applicability of CAGS-F for diagnostic, descriptive, and prescriptive inquiry into SEPs derives from analytic dualism. Analytic dualism (Archer 1995) is reflected in the disaggregation of institutions, organizations, and people across scales and levels. While human, non-human, and natural systems are coupled components of socio-ecological systems, each operates at different scales and levels with complex, nonlinear interactions requiring analytical separation. Separation of institutions, organizations, and people as distinct components of governance systems is absolutely necessary for detecting goal displacement and drift in how mechanisms of power and privilege operate through formal and informal institutions and inform how organizations implement and enforce goals and objectives. Separating out legislation, policy processes, and organizational operations across scales and levels, including the actions of people fulfilling official roles, allows for identification of variation in barriers, opportunities, leverage points, and resources, including allies, for progressive change. Importantly, analytic dualism helps users of CAGS-F to identify where, at what level and scale, who is included and/or adversely affected, and at which point in the adaptive cycle opportunities, barriers, and leverage points exist so as to optimize design, planning, programming, and implementation of SEP initiatives, or evaluate unintended and unforeseen or less than successful outcomes.

\section{What are the benefits of CAGS-F for socio-ecological practice?}

CAGS-F is a novel systems level framework that offers guidance, organization, and basic conceptualizations of concepts and terms for diagnostic, descriptive, and prescriptive inquiry into how institutional and organizational structures and processes and the activities of diverse groups of people across levels and scales produce differential outcomes, barriers, opportunities, and leverage points for achieving progressive SEP goals, such as greater justice and sustainability. CAGS-F synthesizes widely used theories of institutions, organizations, and intersectionality and stratification with the panarchy heuristic within a critical realist orientation. The focus on governance narrows attention to the specific institutions, organizations, and people involved in and affected by specific SEPs. The framework employs analytic dualism to help scientists, scholars, and practitioners examine discrete multidimensional pressures, constraints, and feedbacks across the institutions, organizations, and people of particular governance systems. Intersectional and stratification theories add an ability to understand and include diverse realities and differential capacities. Critical realism helps to make the invisible, unacknowledged, and disregarded forces and relations of power and privilege that produce unintended and undesirable outcomes and injustices, visible so as to contribute to progressive SEP goals.

As Calderon-Contreras and White (2020) noted, diversity is a critical component of flexibility and responsiveness in governing SESs, as well as the ability to produce just outcomes. Each individual and group of individuals brings material and non-material resources, skills, ways of seeing, understanding, and doing, and means of accessing additional resources through social networks, which improves problem solving, programmatic correctives, and responses to unexpected challenges. However, experiences and dispositions, valuation of knowledge, skills, relations, and other resources, and opportunities and barriers vary by stratified positionality within and across institutional, organizational, and everyday contexts. Scholars, researchers, and practitioners must be able to disaggregate social, organizational, and institutional components to adequately capture opportunities, barriers, and potentials for considering and including social diversity in the system to ensure just outcomes. CAGS-F provides tools to examine how social structures and processes across levels and scales of SESs differentially affect and are affected by diverse groups operating within and across institutional and organizational contexts. Guidance and an orientation sensitive to diversity, power, and privilege are provided without closing the research process to surprising and unexpected results. We must be attuned to equity issues, but also people's resourceful capacities, experiences, and perceptions outside normative assumptions. The starting point, therefore, following Bourdieu (1990), is social practices accessible through empirical research, with a comparative examination of institutions, organizations, and SEP processes and outcomes to discern deeper dimensions that structure opportunities and potentials for socio-ecological justice.

\section{Appendix}

See Table 2. 


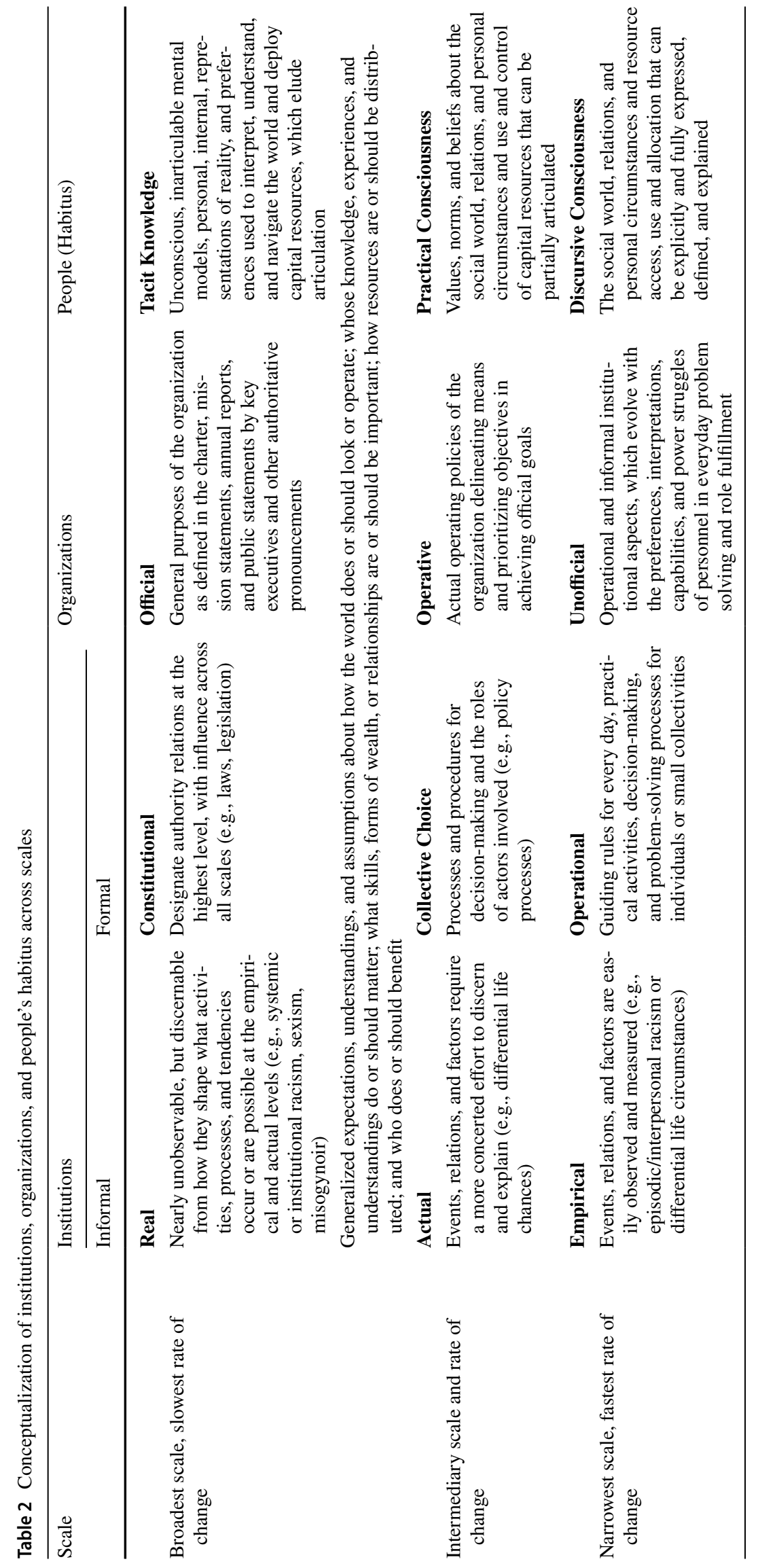




\section{References}

Abidi-Habib M, Lawrence A (2007) Revolt and remember: how the Shimshal nature trust develops and sustains social-ecological resilience in Northern Pakistan. Ecol Soc 12(2):35

Abrams J, Huber-Stearns H, Steen-Adams M, Davis EJ, Bone C, Nelson MF, Moseley C (2020) Adaptive governance in a complex social-ecological context: emergent responses to a native forest insect outbreak. Sustain Sci. https://doi.org/10.1007/ s11625-020-00843-5

Agrawal A (1999) Enchantment and disenchantment: the role of community in natural resource conservation. World Dev 27(4):629-649

Archer MS (1995) Realist social theory: the morphogenetic approach. Cambridge University Press, Cambridge

Archer MS (2003) Structure, agency and the internal coversation. Cambridge University Press, Cambridge

Baird J, Plummer R, Schultz L, Armitage D, Bodin Ö (2019) How does socio-institutional diversity affect collaborative governance of social-ecological systems in practice? Environ Manag 63:200-214

Bhaskar R (2008) A realist theory of science. Routledge, London

Blaser M (2014) Ontology and indigeneity: on the political ontology of heterogeneous assemblages. Cult Geogr 21(1):49-58. https:// doi.org/10.1177/1474474012462534

Bourdieu P (1984) Distinction: a social critique of the judgement of taste. Translated by R. Nice. Harvard University Press, Cambridge

Bourdieu P (1985) The Social Space and the Genesis of Groups. Theory Soc 14(6):723-744

Bourdieu P (1990) The logic of practice. Translated by R. Nice. Stanford University Press, Stanford

Bourdieu P, Wacquant LJD (1992) An invitation to reflexive sociology. University of Chicago Press, Chicago

Brubaker R (2002) Ethnicity without groups. Eur J Sociol 43(2):163-189

Brunner RD (2010) Adaptive governance as a reform strategy. Policy Sci 43(4):301-341. https://doi.org/10.1007/s11077-010-9117-z

Calderon-Contreras R, White CS (2020) Access as the means for understanding social-ecological resilience: bridging analytical frameworks. Soc Nat Resour 33(2):205-223. https://doi.org/10. $1080 / 08941920.2019 .1597233$

Carolan MS (2005) Society, biology, and ecology: bringing nature back into sociology's disciplinary narrative through critical realism. Organ Environ 18(4):393-421

Cash DW, Adger WN, Berkes F, Garden P, Lebel L, Olsson P, Pritchard L, Young O (2006) Scale and cross-scale dynamics: governance and information in a multilevel world. Ecol Soc 11(2):8

Chaffin BC, Craig RK, Gosnell H (2014) Resilience, adaptation, and transformation in the klamath river basin social-ecological system. Idaho Law Rev 51(1):157-193

Chaffin BC, Garmestani AS, Gunderson LH, Benson MH, Angeler DG, Arnold CA, Cosens B, Craig RK, Ruhl JB, Allen CR (2016) Transformative environmental governance. Annu Rev Environ Resour 41:399-423

Cole DH, Epstein G, McGinnis MD (2019) Combining the IAD and SES frameworks. Int J Commons 13(1):244-275. https://doi.org/ 10.18352/ijc.864

Collins PH (2010) The new politics of community. Am Sociol Rev 75(1):7-30. https://doi.org/10.1177/0003122410363293

Cooke SJ, Jeanson AL, Bishop I, Bryan BA, Chen C, Cvitanovic C, Fen Y, Forester J, Fürst C, Hu J, La Rosa D, Meurk C, Nguyen VM, Paolisso M, Qi Y, Chun FKS, Szetey K, Wang X, Wang Y, Archibald CL, Young N (2021) On the theory-practice gap in the environmental realm: perspectives from and for diverse environmental professionals. Socio Ecol Pract Res. https://doi.org/10. 1007/s42532-021-00089-0
Cosens B, Gunderson L (eds) (2018) Practical panarchy for adaptive water governance: linking law to socio-ecological resilience. Springer International, Cham

Crawford SES, Ostrom E (1995) A grammar of institutions. Am Polit Sci Rev 89(3):582-600. https://doi.org/10.2307/2082975

de Kraker J (2017) Social learning for resilience in social-ecological systems. Curr Opin Environ Sustain 28:100-107

Djoudi H, Locatelli B, Vaast C, Asher K, Brockhaus M, Basnett Sijapati B (2016) Beyond dichotomies: gender and intersecting inequalities in climate change studies. Ambio 45:S248-S262. https:// doi.org/10.1007/s13280-016-0825-2

Evans SM, Peller P (2015) A brief history of hutterite demography. Great Plains Q 35(1):79-101

Fabinyi M, Evans L, Foale SJ (2014) Social-ecological systems, social diversity, and power: insights from anthropology and political ecology. Ecol Soc 19(4):12

Fanon F (1986) Black skin, white masks. Translated by C. L. Markmann. Pluto Press, London

Fernández-Giménez ME, Augustine DJ, Porensky LM, Wilmer H, Derner JD, Briske DD, Olsgard Stewart M (2019) Complexity fosters learning in collaborative adaptive management. Ecol Soc 24(2):29. https://doi.org/10.5751/ES-10963-240229

Fischer J, Gardner TA, Bennett EM, Balvanera P, Biggs R, Carpenter S, Daw T, Folke C, Hill R, Hughes TP, Luthe T, Maass M, Meacham M, Norstrom AV, Peterson G, Queiroz C, Seppelt R, Spierenburg M, Tenhunen J (2015) Advancing sustainability through mainstreaming a socialecological systems perspective. Curr Opin Environ Sustain 14:144-149

Flatschart E (2017) Feminist standpoints and critical realism. The contested materiality of difference in intersectionality and new materialism. J Crit Realism 16(3):284-302

Folke C, Hahn T, Olsson P, Norberg J (2005) Adaptive governance of social-ecological systems. Annu Rev Environ Resour 30:441-473. https://doi.org/10.1146/annurev.energy.30.050504.144511

Forester J (2020) Five generations of theory-practice tensions: enriching socio-ecological practice research. Socio Ecol Pract Res 2(1):111-119. https://doi.org/10.1007/s42532-019-00033-3

Fraser N (1995) From redistribution to recognition-dilemmas of justice in a post-socialist age. New Left Rev 212:68-93

Garmestani A, Twidwell D, Angeler DG, Sundstrom S, Barichievy C, Chaffin BC, Eason T, Graham N, Granholm D, Gunderson L, Knutson M, Nash KL, Nelson RJ, Nystrom M, Spanbauer TL, Stow CA, Allen CR (2020) Panarchy: opportunities and challenges for ecosystem management. Front Ecol Environ 18(10):576-583. https://doi.org/10.1002/fee.2264

Giddens A (1984) The constitution of society: outline of the theory of structuration. University of California Press, Berkeley

Giddens A (1990) The consequences of modernity. Stanford University Press, Stanford

Goldman MJ, Turner MD, Daly M (2018) A critical political ecology of human dimensions of climate change: epistemology, ontology, and ethics. WIRE Clim Change 9(4):526. https://doi.org/10.1002/ wcc. 526

Graef DJ, Motzer N, Kramer JG (2021) The value of facilitation in interdisciplinary socio-environmental team research. Socio Ecol Pract Res 3(2):109-113. https://doi.org/10.1007/ s42532-021-00082-7

Gonda N (2017) Revealing the patriarchal sides of climate change adaptation through intersectionality a case study from Nicaragua. In: Buckingham S, LeMasson V (eds) Understanding climate change through gender relations, pp 173-89

Guba EG, Lincoln YS (2005) Paradigmatic controversies, contradictions, and emerging confluences. In: Denzin NK, Lincoln YS (eds) The Sage handbook of qualitative research, 3rd edn. Sage, Thousand Oaks, pp 191-215 
Gunderson LH, Holling CS (eds) (2002) Panarchy: understanding transformations in human and natural systems. Island Press, Washington

Honneth A (1995) The struggle for recognition: the moral grammar of social conflicts. Translated by J. Anderson. The MIT Press, Cambridge

Hoover FA, Lim TC (2021) Examining privilege and power in us urban parks and open space during the double crises of antiblack racism and Covid-19. Socio Ecol Pract Res 3(1):55-70. https://doi.org/ 10.1007/s42532-020-00070-3

Kaijser A, Kronsell A (2014) Climate change through the lens of intersectionality. Environ Polit 23(3):417-433. https://doi.org/10.1080/ 09644016.2013 .835203

Karpouzoglou T, Dewulf A, Clark J (2016) Advancing adaptive governance of social-ecological systems through theoretical multiplicity. Environ Sci Policy 57:1-9. https://doi.org/10.1016/j. envsci.2015.11.011

Kimmerer RW (2018) Mishkos Kenomagwen, the lessons of grass: restoring reciprocity with the good green earth. In: Nelson MK, Shilling D (eds) Traditional ecological knowledge: learning from indigenous practices for environmental sustainability. Cambridge University Press, Cambridge, pp 27-56

Kiser L, Ostrom E (1982) The three worlds of action: A metatheoretical synthesis of institutional approaches. In: Ostrom E (ed) Strategies of political inquiry. Sage, Beverly Hills, pp 179-222

Kondo Y, Fujisawa E, Ishikawa K, Nakahara S, Matsushita K, Asano S, Kamatani K, Suetsugu S, Kano K, Kumazawa T, Sato K, Okuda $\mathrm{N}$ (2021) Community capability building for environmental conservation in Lake Biwa (Japan) through an adaptive and abductive approach. Socio Ecol Pract Res 3(2):167-183. https://doi.org/10. 1007/s42532-021-00078-3

Leach M, Mearns R, Scoones I (1997) Challenges to community based sustainable development-dynamics, entitlements, Institutions. Ids Bull Inst Dev Stud 28(4):4-14

Martinez A, Martin L, Marlow S (2014) Developing a critical realist positional approach to intersectionality. J Crit Realism 13(5):447-466

May CK (2015) Politics of visibility: competing for legitimacy in North Carolina fisheries governance. Eviron Plann C Gov Policy 33(6):1484-1500

May CK (2021a) Institutional panarchy: adaptations in socio-hydrological governance of the South Dakota Prairie Pothole Region, USA. J Envion Manag. https://doi.org/10.1016/j.jenvman.2021.112851

May CK (2021b) Coastal community resilience and power: a comparative analysis of adaptability in North Carolina and Louisiana. Environ Manag 68(1):100-116

McGinnis MD, Ostrom E (2014) Social-ecological system framework: initial changes and continuing challenges. Ecol Soc 19(2):30. https://doi.org/10.5751/ES-06387-190230

McGinnis MD (2011) An introduction to Iad and the language of the Ostrom workshop: a simple guide to a complex framework. Policy Stud J 39(1):169-183

Nightingale AJ (2016) Adaptive scholarship and situated knowledges? Hybrid methodologies and plural epistemologies in climate change adaptation research. Area 48(1):41-47. https://doi.org/ 10.1111/area.12195

Nightingale AJ (2017) Power and politics in climate change adaptation efforts: struggles over authority and recognition in the context of political instability. Geoforum 84:11-20. https://doi.org/10.1016/j. geoforum.2017.05.011

North DC (1991) Institutions. J Econ Perspect 5(1):97-112. https://doi. org/10.1257/jep.5.1.97

Olsson L, Jerneck A, Thoren H, Persson J, O’Byrne D (2015) Why resilience is unappealing to social science: theoretical and empirical investigations of the scientific use of resilience. Sci Adv 1(4):e1400217
Ostrom E (2011) Background on the institutional analysis and development framework. Policy Stud J 39(1):7-27

Perkins PE (2019) Climate justice, commons, and degrowth. Ecol Econ. https://doi.org/10.1016/j.ecolecon.2019.02.005

Perrow C (1961) The analysis of goals in complex orgainzations. Am Sociol Rev 26(6):854-866

Perrow C (1986) Complex orgainzations: a critical essay. Random House, New York

Prescod-Weinstein C (2020) Making black women scientists under white empiricism: the racialization of epistemology in physics. Signs J Women Cult Soc 45(2):421-447. https://doi.org/10.1086/ 704991

Ray V (2019) A theory of racialized organizations. Am Sociol Rev 84(1):26-53

Reyers B, Folke C, Moore ML, Biggs R, Galaz V (2018) Social-ecological systems insights for navigating the dynamics of the anthropocene. Annu Rev Environ Resour 43:267-289. https://doi.org/ 10.1146/annurev-environ-102017-085349

Rothstein R (2017) The color of law: a forgotten history of how our government segregated America. Liveright Publishing, New York

Saint-Onge H (1996) Tacit knowledge: the key to the strategic alignment of intellectual capital. Plan Rev 24(2):10-16. https://doi. org/10.1108/eb054547

Schlager E, Ostrom E (1992) Property-rights regimes and naturalresources-a conceptual analysis. Land Econ 68(3):249-262. https://doi.org/10.2307/3146375

Schlamovitz JL, Becker P (2020) Differentiated vulnerabilities and capacities for adaptation to water shortage in Gaborone, Botswana. Int J Water Resour Dev. https://doi.org/10.1080/07900 627.2020 .1756752

Selznick P (1949) TVA and the grass roots: a study in the sociology of formal organization. University of California Press, Berkeley

Sewell WH Jr (1992) A theory of structure-duality, agency, and transformation. Am J Sociol 98(1):1-29

Shi L (2020) Beyond flood risk reduction: how can green infrastructure advance both social justice and regional impact? Socio Ecol Pract Res 2(4):311-320. https://doi.org/10.1007/ s42532-020-00065-0

Smith DE (1990) The conceptual practices of power: a feminist sociology of knowledge. North Eastern University Press, Boston

Sultana F (2020) Political ecology 1: from margins to center. Prog Hum Geogr. https://doi.org/10.1177/0309132520936751

Taylor DE (2015) Gender and racial diversity in environmental organizations: uneven accomplishments and cause for concern. Environ Justice 8(5):165-180. https://doi.org/10.1089/env.2015.0018

Thoms MC, Meitzen KM, Julianb JP, Butler DR (2018) Bio-Geomorphology and resilience thinking: common ground and challenges. Geomorphology 305:1-7

Tschakert P (2012) From impacts to embodied experiences: tracing political ecology in climate change research. Danish J Geogr 112(2):144-158. https://doi.org/10.1080/00167223.2012.741889

Tschakert P, Dietrich K, Tamminga K, Prins E, Shaffer J, Liwenga E, Asiedu A (2014) Learning and envisioning under climatic uncertainty: an African experience. Environ Plan A 46(5):1049-1068. https://doi.org/10.1068/a46257

Turnhout E, Metze T, Wyborn C, Klenk N, Louder E (2020) The politics of co-production: participation, power, and transformation. Curr Opin Environ Sustain 42:15-21. https://doi.org/10.1016/j. cosust.2019.11.009

Vonk M (2011) Sustainability and quality of life: a study on the religious worldviews, values and environmental impact of Amish, Hutterite, Franciscan and Benedictine Communities. Buijten \& Schipperheijn, Amsterdam 
Walby S (2007) Complexity theory, systems theory, and multiple intersecting social inequalities. Philos Soc Sci 37(4):449-470. https:// doi.org/10.1177/0048393107307663

Walby S, Armstrong J, Strid S (2012) Intersectionality: multiple inequalities in social theory. Sociology 46(2):224-240. https://doi. org/10.1177/0038038511416164

Walker B, Holling CS, Carpenter SR, Kinzig A (2004) Resilience, adaptability and transformability in social-ecological systems. Ecol Soc 9(2):5

Walker B, Salt D (2006) Resilience thinking: sustaining ecosystems and people in a changing world. Island Press, Washington, DC

Weber M (1978) Economy and Society: An Outline of Interpretive Sociology. In: Roth G, Wittich C (eds), vol 2. University of California Press, Berkeley

Winkel T, Nunez-Carrasco L, Cruz PJ, Egan N, Saez-Tonacca L, Cubillos-Celis P, Poblete-Olivera C, Zavalla-Nanco N, Mino-Baes B, Viedma-Araya MP (2020) Mobilising common biocultural heritage for the socioeconomic inclusion of small farmers: panarchy of two case studies on Quinoa in Chile and Bolivia. Agric Hum Values. https://doi.org/10.1007/s10460-019-09996-1

Winker G, Degele N (2011) Intersectionality as multi-level analysis: dealing with social inequality. Eur J Women's Stud 18(1):51-66. https://doi.org/10.1177/1350506810386084

Wyborn C (2015) Co-productive governance: a relational framework for adaptive governance. Global Environ Change Hum Policy Dimens 30:56-67. https://doi.org/10.1016/j.gloenvcha.2014.10. 009

Xiang W-N (2021) Seven approaches to research in socio-ecological practice \& five insights from the RWC-Schön-Stokes model. Socio Ecol Pract Res 3(1):71-88. https://doi.org/10.1007/ s42532-021-00073-8

Xiang W-N (2019) Ecopracticology: the study of socio-ecological practice. Socio Ecol Pract Res 1(1):7-14. https://doi.org/10.1007/ s42532-019-00006-6
Xu L, Marinova D, Guo X (2015) Resilience thinking: a renewed system approach for sustainability science. Sustain Sci 10:123-138

Young IM (1990) Justice and the politics of difference. Princeton University Press, New Jersey

Young OR (2006) Vertical interplay among scale-dependent environmental and resource regimes. Ecol Soc 11(1):27

Zucker LG (1982) Organizations as institutions. In: Bacharach SB (ed) Research in the sociology of organizations, vol 2. JAI Press, Greenwich, pp 1-47

Publisher's Note Springer Nature remains neutral with regard to jurisdictional claims in published maps and institutional affiliations.

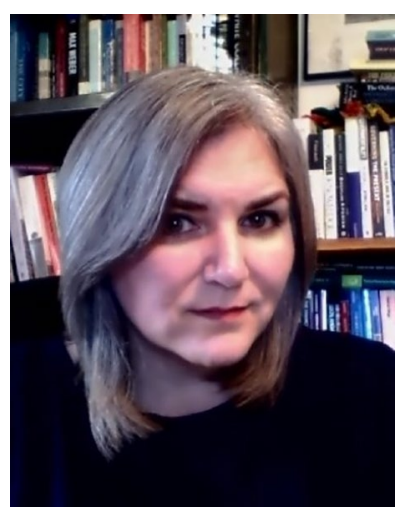

Candace K. May is a Critical Rural and Natural Resources Sociologist in the School of Psychology, Sociology and Rural Studies and the Department of Natural Resources Management at South Dakota State University, USA. She studies communities, collective action, and governance with an explicit focus on multi-dimensional forms of inequality and power for the purpose of working toward a more socioecologically just future. Her work focuses on the actual extent of, potential for, and policy outcomes from the in/exclusion or abstention and cooperation/conflict of diverse groups in socio-ecological governance processes. 